\title{
Based on FDM numerical simulation research on the factors influencing heat release in wet airway
}

\author{
Xuebo Zhang ${ }^{1,2,3}$, Ming Yang $2,3^{*}$ \\ ${ }^{1}$ The Collaborative Innovation Center of Coal Safety Production of Henan Province, Jiaozuo 45400, China \\ ${ }^{2}$ State Key Laboratory Cultivation Base for Gas Geology and Gas Control, Jiaozuo 454003, China \\ ${ }^{3}$ School of Safety Science \& Engineering, Henan Polytechnic University, Jiaozuo 454003, China
}

Corresponding Author Email: Yming2005@163.com

https://doi.org/10.18280/ijht.360127

Received: 27 May 2017

Accepted: 5 March 2018

\section{Keywords:}

surrounding rock temperature, wetness factor, water evaporation, heat release, moisture content.

\begin{abstract}
The objective of the paper is to figure out the influence factors of surrounding rock heat release in wet airway. Firstly, based on the heat and moisture exchange theory between airflow and the surrounding rock in coal mine, the more reliable method of calculating the surrounding rock heat release in wet airway is put forward in theory, and the finite difference method is applied to calculate numerical simulation results. Accordingly the change rule of surrounding rock heat release under this condition is presented. Finally the influences of ventilation time, wetness factor and the like on the surrounding rock heat release are analyzed in detail. The research results indicate that, 1) the sensible heat, latent heat and total heat loss decrease with the increase of ventilation time, the decreasing amplitude gradually small; 2) wetness factor has a strong effect on surrounding rock heat release, and the sensible heat decreases with the increase of wetness factor, while the latent heat and total heat increase with it.
\end{abstract}

\section{INTRODUCTION}

In the procession of colliery exploitation, along with the increasing thickness of the coal mines and the improvement of mechanized extraction, the deep mine high temperature and heat has become one of the most seriously problems in deep mines, which does harm to the miners healthy and restricts the further improvement of mine productive efficiency. Strata rock heat is the main heat source of mine. Research on the calculation of heat release has been undertaken by a number of researchers for a wide range of conditions [1-9]. The calculation methods of underground thermal environment prediction have been revealed. Qin Yueping [10]carries on the dimensionless analysis to the differential equation of heat conduction and the equation treated by the finite volume method. Kong Song [11] studied the theory of wind temperature prediction in high temperature coal mining face, established the mathematical model of the temperature field of the surrounding rock of the coal mining face, the mathematical model of the thermal emission from the goaf, the theoretical model and the temperature field of the surrounding rock of the working face, and carried out numerical simulation. Through numerical simulation and laboratory experiments, Song Huaitao [12] studied the variation law of the temperature field of the surrounding rock under the periodic change of the wind temperature. Gao Jianliang [13] established the mathematical equations of temperature distribution, wall and air heat and moisture exchange, air temperature and humidity changes under the condition of evaporation of wall water and airflow at the same time.Wang Yijiang [14]has studied the mechanism of heat and mass transfer of surrounding rock for thermal damage mine by means of physical experiment, numerical simulation and theoretical analysis. However, for the actual condition of the underground complex, many factors affect the change of airflow state, so all kinds of calculation methods have some limitations, which makes the rock heat calculation result has great errors. Therefore, the accurate calculation of heat release in wet airway, master the changing rule of heat release and its influence factors, research on the effective control of the thermal environment of underground workplace and high temperature mine cooling technology, has become the world mining industry problems to be solved, which also is an important and urgent task for mining science and technology workers.

A theoretically more reliable method to determine the surrounding rock heat release was put forward according to the study on the principles of heat-and moisture- transfer between airflow and the surrounding rock in mine. A program is coded to simulate the changing rule of heat release in wet airway. The impact of ventilation time and wetness factor on airway surface on the changing rule of heat release is analyzed in this paper.

\section{CAlCulation OF heAT RELEASE IN WET AIRWAY}

A mathematical model describing the heat- and moisturetransfer between mine air and the surrounding rock mass can be developed on the basis of the following acceptable assumptions:

(1) Cross-section of the airway is considered to be circular;

(2) Rock mass surrounding the airway is thermally homogeneous and isotropic, having a uniform distribution of virgin rock temperature;

(3) Heat transfer coefficient and conductive coefficient are constant parameter; do not vary with temperature;

Within the envelope of rock that surrounds an underground airway, the temperature varies with both position and time. 


\subsection{Heat transfer in surrounding rock}

Within the envelope of rock that surrounds an underground airway, the temperature varies with both position and time. It obeys the following equation [15]:

$$
\frac{\partial T}{\partial t}=a\left(\frac{\partial^{2} T}{\partial r^{2}}+\frac{1}{r} \frac{\partial T}{\partial r}+\frac{\partial^{2} T}{\partial z^{2}}\right) \quad\left(r_{0}<r<\infty\right)
$$

where $a$ is thermal diffusivity of the rock surrounding airway, $r$ is the distance from the airway surface, $z$ is the length of the airway, $T$ is the rock temperature, and $t$ is the ventilation time of airway.

\subsection{Calculation of heat release}

On the airway surface, part of the strata rock heat (latent heat) is use for water evaporation, part of (sensible heat) is use to raise the temperature of airflow.

According to the convective heat transfer law, the sensible heat qs from unit surface area release to the airflow can calculate by the following equation.

$q_{s}=\alpha\left(T_{w}-T_{f}\right)$

where $q_{s}$ is sensible heat transfer rate into airflow, $T_{w}$ is rock surface temperature, $T_{f}$ is temperature of airflow in the airway, $\alpha$ is convection heat-transfer coefficient.

Generally speaking, mostly roadway surface is wet, moist degree of surface commonly used to represent the wetness factor on airway surface $f$. The wetness factor $f$ is defined as the ratio of water vapor evaporation from the water evaporation amount and the assumption of roadway wall part wet roadway surface evaporation surface completely wet [16, 17]. Water vapor quality transfer from part of wet roadway surface per unit area to the airflow as follows.

$m_{s}=f \sigma\left(m_{w}-m\right)$

where $m_{w}$ is moisture content of air on completely wet airway surface, $m$ is moisture content of air in airflow, and $\delta$ is convection mass-transfer coefficient.

So, the latent heat $q_{1}$ from unit surface area release to the airflow can calculate by the following equation.

$q_{l}=f \sigma L_{v}\left(m_{w}-m\right)$

where $q_{l}$ is latent heat transfer rate into airflow, and $L_{v}$ is latent heat of water evaporation.

The strata heat release $q_{t}$ is equal to the latent heat $q_{l}$ and sensible heat $q_{s}$, which can establish the heat balance equation at the surface of airway. That is,

$q_{t}=q_{s}+q_{l}$

The sensible heat, latent heat and strata heat release $q_{t}$ can be calculated by the above equation.

\section{FINITE DIFFERENCE METHOD}

Finite Difference Method (FDM) is an effective means of obtaining the numerical solutions of differential equations and was successfully used to simulate thermal environmental problems by many researchers (e. g. Yanagimoto et al., 1974, 1980; Uchino et al., 1982; Inoue et al., 1986).FDM according to the interval of time interval and space, time and space area is divided into several grids, with unknown function in grid point values of the difference approximation the derivative in control equation, then the solution of algebraic equations for the unknown function changes in time and space (the numerical solution). In this study the Finite Difference Method will be used to obtain the numerical solution of the above equations.

Variable intervals are adopted to form the mesh grid. The grids near the rock surface are formed with narrow intervals in order to calculate the rock temperature more accurately at the initial stage of cooling. The intervals are made to expand with deeper into the strata. Grid mesh in surrounding rock is shown in Figure 1.

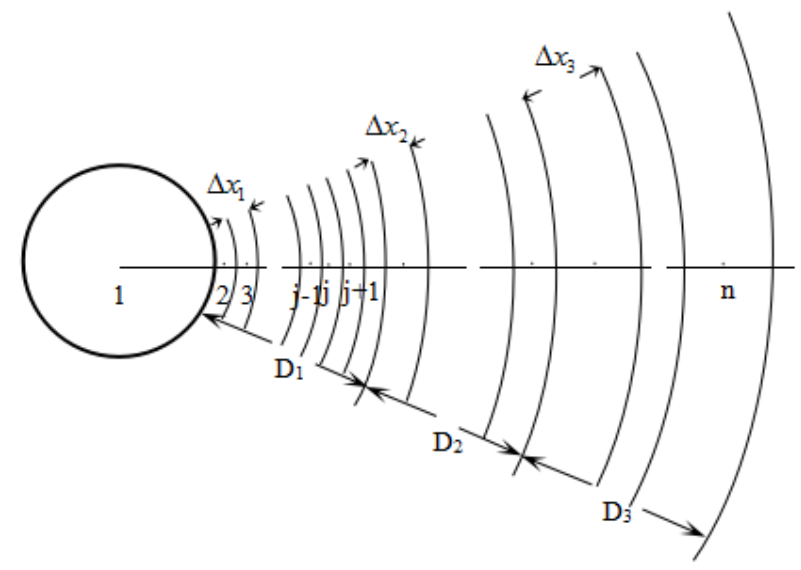

Figure 1. Grid mesh in surrounding rock

\subsection{Algorithm of strata rock temperature calculation}

The following equation is established to calculate the temperature in surrounding rock according to principle of heat balance.

$\left.\lambda \frac{\partial T}{\partial r}\right|_{r=r_{0}}=\alpha\left(T_{w}-T_{f}\right)+f \sigma L_{v}\left(m_{w}-m\right) \quad(t>0)$

$$
\begin{aligned}
& {\left[\lambda \cdot \frac{T_{j-1}-T_{j}}{\frac{\Delta x(j-1)+\Delta x(j)}{2}} \cdot \sum_{i=1}^{j-1} \Delta x(i) \cdot 2 \pi+\lambda \cdot \frac{T_{j+1}-T_{j}}{\frac{\Delta x(j+1)+\Delta x(j)}{2}} \cdot \sum_{i=1}^{j} \Delta x(i) \cdot 2 \pi\right] \cdot \Delta \tau} \\
& =\rho_{\text {rock }} C_{p}\left(T_{j}^{\prime}-T_{j}\right) \cdot\left[2 \pi\left(\sum_{i=1}^{j} \Delta x(i)+\frac{\Delta x(j)}{2}\right) \cdot \Delta x(j)\right]
\end{aligned}
$$

where $T_{j}{ }^{\prime}$ is rock temperature at point $\mathrm{j}$ after time interval $\Delta \tau$; $C_{p}$ is specific heat of rock; $\rho_{\text {rock }}$ is density of surrounding rock. 
If $A=\frac{\sum_{i=1}^{j-1} \Delta x(i)}{\frac{\Delta x(j-1)+\Delta x(j)}{2}} \quad B=\frac{\sum_{i=1}^{j} \Delta x(i)}{\frac{\Delta x(j+1)+\Delta x(j)}{2}}$
$D=\sum_{i=1}^{j-1} \Delta x(i)+\frac{\Delta x(j)}{2} \quad M=\frac{\Delta x^{2}}{a \Delta t}$

Then equation 7 can be transferred into:

$T_{j}^{\prime}=\frac{1}{M D}\left[A T_{j-1}+B T_{j+1}+(D M-A-B) T_{j}\right]$

The rock temperature at points from 3 to $n$ can be calculated by above equation. In order to calculate the rock temperature at point 2 which is next to the airway surface, the airway surface temperature $T_{w}$ should be obtained. The airway surface temperature $T_{w}$ can be derived according to boundary condition equation 4. Besides of the airway surface temperature $T_{w}$, here also another important variable $m_{w}$ must be decided. $m_{w}$ is defined as the saturated moisture content of air on completely wet airway surface.

\subsection{Determine airway surface humidity}

In equation $4 m_{w}$ is saturated vapor concentration very near the airway surface. If the wall surface is completely covered or coated with liquid water, it is reasonable to assume that, immediately adjacent to the liquid surface, the air will be saturated. The moisture content is thus equal to the saturated vapor concentration $m_{w}$ at surface temperature $T_{w}$ [7-8] Therefore, $m_{w}$ is a function of the surface temperature. The variation of saturated moisture content with the temperature is shown in Figure 2, which is usually expressed by a linear equation approximately[7-8]. From the figure it can be seen that the saturated moisture content does not vary linearly with the temperature. The great error would be caused if the linear relationship is taken to decide the moisture content very near to the airway surface.

The relationship between $m_{w}$ and $T_{w}$ can be fitted as a quadratic curve which is shown as Fig. 2.

$m_{w}=k_{0}+k_{1} T+k_{2} T^{2} \quad\left(20^{\circ} \mathrm{C} \sim 50^{\circ} \mathrm{C}\right)$

where $k_{0}, k_{1}, k_{2}$ is regression constants, It can be seen than the quadratic curve fits well with the actual data.

The moisture content in airflow of relative humidity $\phi c$ an be expressed as:

$m=\phi\left(k_{0}+k_{1} T+k_{2} T^{2}\right)$

The saturated moisture content of air mw can be used in the solving process, which is a single value function of the temperature.

In order to calculate conveniently, the relationship between saturated moisture content of air and temperature was usually simple fitted into a linear curve [8-10], but the relationship between them is nonlinear. In order to accurately calculate the saturated air moisture content, the relationship between saturated moisture content of air and temperature was fitted into a quadratic curve in this paper (Figure 2).
Base on the above algorithm, a program is coded to simulate the changing rule of heat release in wet airway. The axial and radial heat conduction in surrounding rock, the heat exchange between strata and airflow, the water evaporation on surface of strata and other factors are taken in considered in the program. Program scheme of calculation program is shown in Figure 3. An example is taken to show the variation of heat release and its influencing factors in wet airway.

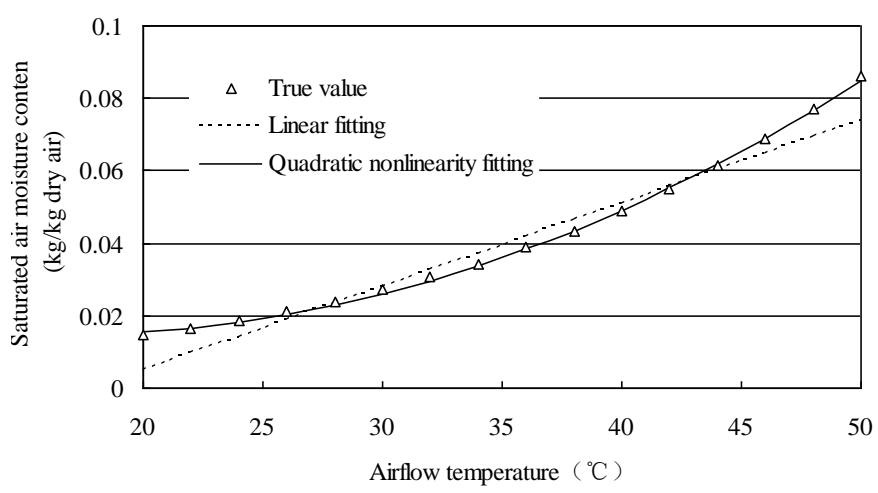

Figure 2. Relationship between moisture content of saturated air and temperature

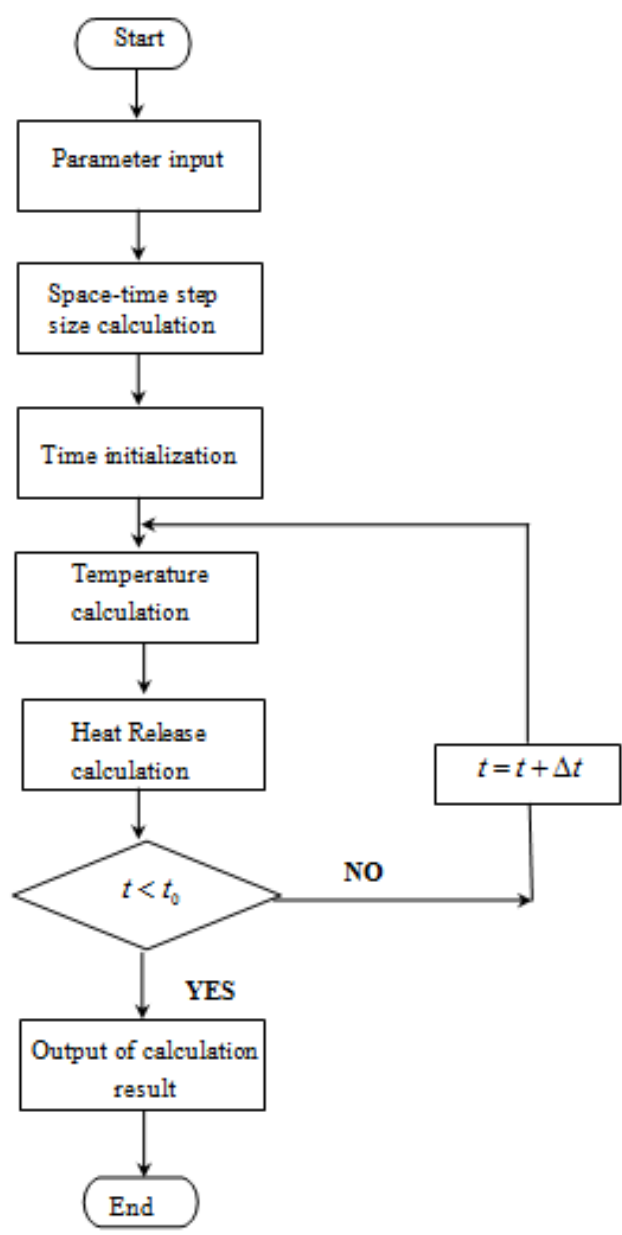

Figure 3. Program scheme of calculation

\section{STUDY ON THE INFLUENCING FACTORS OF HEAT RELEASE IN WET AIRWAY}

The simulation model assumes a circular roadway of diameter $2 \mathrm{~m}$. An airflow of $25^{\circ} \mathrm{C}$ passes at a density of 
$1.2 \mathrm{~kg} / \mathrm{m}^{3}$. The thermal conductivity and the diffusivity of the surrounding rock is taken to be $13.4 \mathrm{~kJ} /\left(\mathrm{m}^{2} \mathrm{~h}^{\circ} \mathrm{C}\right)$ and $3.33 \times 10^{-}$ ${ }^{3} \mathrm{~m}^{2} / \mathrm{h}$, respectively, and heat transfer coefficient on wall surface is taken to be $50.2 \mathrm{~kJ} /\left(\mathrm{m}^{2} \mathrm{~h}^{\circ} \mathrm{C}\right)$. The initial rock temperature is set at a constant value of $60^{\circ} \mathrm{C}$.

\subsection{Influence of airway ventilation time on strata heat} release

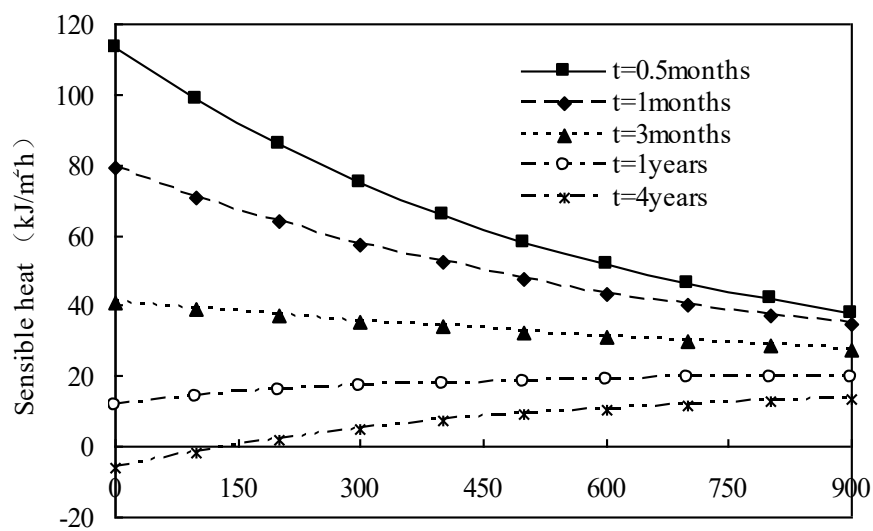

Distance of airflow flow along the roadway(m)

a. the distribution of sensible heat

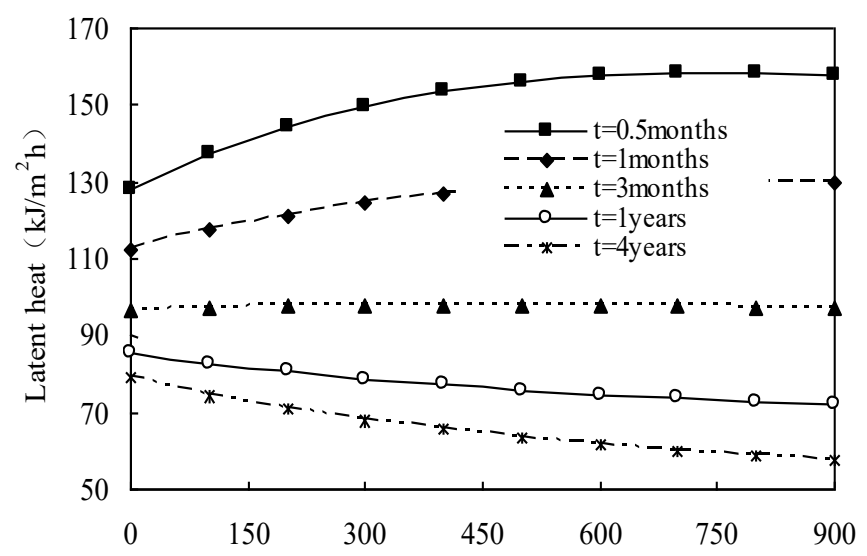

Distance of airflow flow along the roadway(m) b. the distribution of latent heat

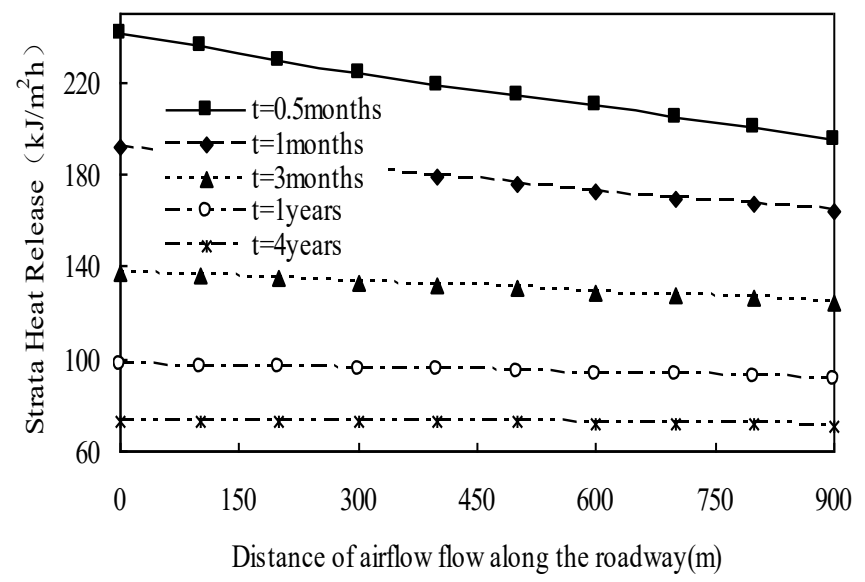

c. the distribution of strata heat release

Figure 4. Distribution of strata heat alone the roadway

Figure 4 shows the distribution rules of sensible heat, latent heat and strata heat release alone the roadway in different ventilation time, respectively, when the relative humidity of the airflow is $75 \%$ and the wetness factor of airway surface is 0.1 .

It can be seen from Figure 4, in the ventilation early sensible heat decreases gradually along the roadway, and latent heat increases gradually. After a period of ventilation time, the sensible heat along the roadway increases gradually, and the latent heat gradually decreases. However, the strata heat release alone the roadway always decreases, the decreasing amplitude of strata heat release is smaller with the longer ventilation time.

\subsection{Influence of wetness factor of airway surface on strata heat release}

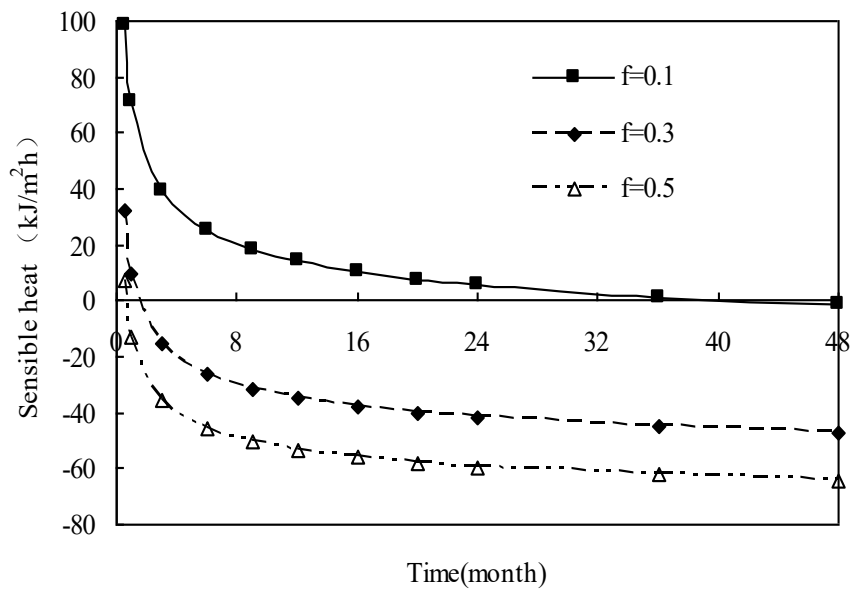

a. Influence of wetness factor on the sensible heat

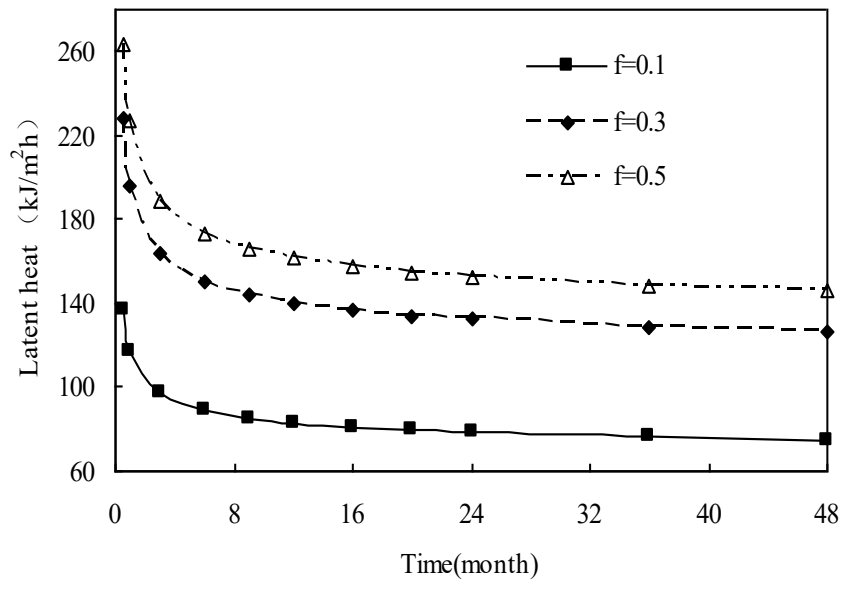

b. Influence of wetness factor on the latent heat

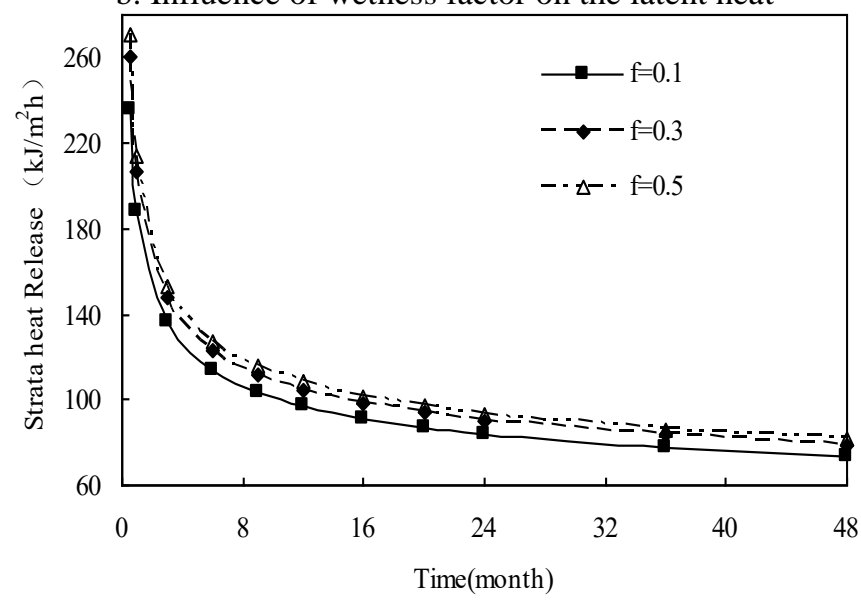

c. Influence of wetness factor on the strata heat release

Figure 5. Influence of wetness factor on the variation of sensible heat, latent heat and strata heat release 
Figure 5 shows the distribution rules of sensible heat, latent heat and strata heat release from the airway entrance at $100 \mathrm{~m}$ with ventilation time, respectively, when the relative humidity of the airflow is $75 \%$ and the wetness factor of airway surface is $0.1,0.3$ and 0.5 respectively.

It can be seen from the Figure 5 that, the wetness factor of airway surface has a greater influence on strata heat release in wet airway. The sensible heat, latent heat and heat release when the wetness factor of airway surface was 0.5 and airway ventilation at 6 months, is $1.82,1.94$ and 1.20 times that of the wetness factor was 0.1 respectively. The sensible heat, latent heat and heat release is decreased with the increase of ventilation time and the reduce rate decrease gradually. On the other hand, the sensible heat from the surface of wet roadway is decreased with the increase of wetness factor, but the latent heat and heat release are increased with that, just because the surface temperature is lower when the surface more humid.

In some cases, the sensible heat is negative, due to the strata surface temperature is lower than the airflow temperature and the strata heat release and heat in airflow is aborted by water on the surface.

\section{FIELD APPLICATION}

The original rock temperature of the surrounding rock is 35 ${ }^{\circ} \mathrm{C}$ and the rock temperature on wall surface is $29.6^{\circ} \mathrm{C}$ when a new mining roadway passes through in a coal mine. The rock temperature on wall surface drops to $28.5^{\circ} \mathrm{C}$ after 3 months of ventilation. Due to the high airflow temperature, the roadway is sprinkled every day and the rock temperature on wall surface drops to $26.4^{\circ} \mathrm{C}$ after 2 months of ventilation. It can be seen that, the surrounding rock continues to heat release and the wall temperature decreases with the extension of the ventilation time.The roadway sprinkler increases the moisture coefficient of the wall surface, and the wall water evaporates and absorbs heat. The strata heat release speed is accelerated and the wall temperature decreases faster. This is in accordance with the results of the previous study.

\section{CONCLUSIONS}

A program is coded to simulate the heat- and massexchange between airflow and wet airway surface. The influence of ventilation time and wetness factor on heat release in wet airway is analyzed. The conclusions are as follows:

1) In the ventilation early, the sensible heat decreases gradually along the roadway and latent heat increases gradually. After a period of ventilation time, the sensible heat along the roadway increases gradually, and the latent heat gradually decreases. However, the strata heat release alone the roadway always decreases, the decreasing amplitude of strata heat release is smaller with the longer ventilation time.

2) The wetness factor of airway surface has a greater influence on strata heat release in wet airway. The sensible heat, latent heat and heat release when the wetness factor of airway surface was 0.5 and airway ventilation at 6 months, is $1.82,1.94$ and 1.20 times that of the wetness factor was 0.1 , respectively.

3) The sensible heat, latent heat and heat release is decreased with the increase of ventilation time and the reduce rate decrease gradually. On the other hand, the sensible heat from the surface of wet roadway is decreased with the increase of wetness factor, but the latent heat and heat release are increased with that, just because the surface temperature is lower when the surface more humid. The results of the field experiment are in agreement with the reseach results.

\section{ACKNOWLEDGEMENTS}

Supported by the National Natural Science Foundation of China (Grant No. 51734007, No.51704099), Henan Province Basic and Frontier Technology Research Projects of China (Grant No.142300413233), Henan Province Major Scientific and Technological Breakthrough Research Project (Grant No.13B440038) and Opening Foundation of State Key Laboratory Cultivation Base for Gas Geology and Gas Control (Grant No.WS2017B14).

\section{REFERENCES}

[1] Starfield AM, Bleloch AL. (1983). A new method for the computation of heat and moisture transfer in partly wet airway. J.S. Afr. Inst. Min. Met 83(11): 263-269.

[2] Uchino K, Inoue M. (1986). New practical method for calculation of air temperature and humidity along wet roadway - the influence of moisture on the underground environment in mines (2nd Report). Journal of the Mining and Metallurgical Institute of Japan 102(6): 353357.

[3] Uchino K, Inoue M. (1990). Improved practical method for calculation of air temperature and humidity along a roadway under complicated conditions - the influence of moisture on the underground environment in mines (3rd Report). Journal of the Mining and Materials Processing Institute of Japan 106(1): 7-12.

[4] Sasaki K, Miyakoshi H, Mashiba K, et a1. (1996). Analytical system for ventilation simulators with skyline nodal pressure method and practical estimate system for underground mine air-conditioning. 26th proceedings of the application of computers and operations research in the mineral industry. Pennsylvania: The Society of Mining, Metallurgy and Explosion Inc. 393-399.

[5] Wang YM, Zhu Y. (1984). Application of computer simulation in study of heat transfer between wet airway surface and airflow. Safety in Coal Mines 15(6): 1-10.

[6] Hou QZ, Shen BX. (1997). The prediction model of temperature and moisture transfer between tunnel periphery rock and air. Journal of Wuhan University of Technology 1997(3): 123-127.

[7] Zhou XH, Shan YF, Wang JR. (2002). Unsteady thermal exchange between wall rock and airflow of roadway. Fuxin: Journal of Liaoning Technical University 21(3): 264-266

[8] Gao JL, Wei PR. (2006). Numerical simulation of the thermal environment at working face of diving airway. Journal of Coal Science \& Engineering 31(2): 201-205. https://doi.org/10.13225/j.cnki.jccs.2002.01.013

[9] Wu Q, Qin YP, Guo L. (2002). Calculation of the heat emitting from the wall rock at drifting face with finite element method. Beijing: China Safety Science Journal (6): 33-36. https://doi.org/10.3321/j.issn:02539993.2006.02.015

[10] Qin YP, Wang J, Hao YJ, etc. (2013). Dimensionless analysis for heat dissipation from surrounding rock in 
roadway. Mining and Metallurgical Engineering 33(3): 5-12. https://doi.org/10.3969/j.issn.0253099.2013.03.002.

[11] Kong S. (2016). Theory and numerical simulation of air temperature forecast in coalface with high temperature. China University of Mining \& Technology, Beijing.

[12] Song HT. (2016). Numerical analysis and experimental research on temperature field of surrounding rock under mine wind temperature periodic change. China University of Mining \& Technology, Beijing.

[13] Gao JL, Xu W, Zhang XB. (2010). Treatment of water evaporation during calculation of temperature and humidity of airflow caused by heat release from surrounding rock. Journal of China Coal Society 35(6): 951-955.
[14] Wang YJ. (2010). Heat and mass transfer of surrounding rock and airflow for deep thermal environment. China University of Mining \& Technology. https://doi.org/10.13225/j.cnki.jccs.2010.06.026

[15] Cen YQ, Hou QZ. (1989). Underground Thermal Environmental Engineering. Wuhan University of Technology Press, Wuhan. 81-99.

[16] Gao JL, Yang M. (2005). Analysis of the factors influencing temperature distribution of surrounding rock and cooled zone radius. Beijing: China Safety Science Journal 15(2): 73-76. https://doi.org/10.3969/j.issn.1003-3033.2005.02.017

[17] Gao JL, Zhang SH, Yang M. (2004). Theoretical analysis of the variation pattern of sensible heat factor. Beijing: China Safety Science Journal, 14(3): 96-98. https://doi.org/10.3969/j.issn.1003-3033.2004.03.024 